\title{
Intervention in health care teams and working relationships
}

This article was published in the following Dove Press journal:

Journal of Healthcare Leadership

20 September 2012

Number of times this article has been viewed

\author{
Mary Laurenson \\ Tracey Heath \\ Sarah Gribbin \\ University of Hull, Faculty of Health \\ and Social Care, Department \\ of Health Professional Studies, \\ Cottingham, Hull, United Kingdom
}

Introduction: Communication is an intrinsic part of collaborative working but can be problematic when the complexities of professional and personal identities inhibit quality care provision. This paper investigates these complexities and recommends interventions to facilitate collaborative working.

Methods: A qualitative comparative approach examined data collected from participants using purposive non-probability sampling. Perspectives were obtained from four professional groups (nurses, social workers, care managers, and police), from different organizations with different theoretical and practice frameworks, and from a fifth group (informal carers).

Results: Curriculum change and leadership initiatives are required to address the complexities inhibiting collaborative working relationships. Integrating complexity theory, personality typology, and problem-based learning into the curriculum to understand behavioral actions will enable interventions to effect change and promote the centrality of those being cared for.

Keywords: interprofessional education and working, complexity, communication, personality, problem-based learning

\section{Introduction}

Effective collaboration in health and social care (H\&SC) is central to delivering high quality practice and services; however, communication difficulties between professions can inhibit care delivery. To solve this problem, an understanding of theoretical and practice frameworks is required to facilitate interdependence and dialogue. ${ }^{1,2}$ Additionally, insight into professional relationships and personality typology may highlight how thought processes and actions can lead to compatibility or conflict.

Recent H\&SC reports ${ }^{3,4}$ cite significant care standards failures and demand improvement, offering a range of contributory factors and solutions which need to be addressed if recurrences are to be prevented and high quality care assured. A consistent theme within these reports is the call for effective interprofessional working (IPW). Nonetheless, despite endorsement of IPW, the route to its successful delivery remains elusive, although it is recognized that effective communication is paramount and that this in turn requires an understanding of both different professional perspectives and the dynamic nature of professional relationships. ${ }^{5-10}$ Hence developing teamwork skills is of paramount importance in interprofessional education (IPE) to bridge the gap between the service providers' organizations and professionals. ${ }^{6,10,11}$ Certainly the situation is complex, therefore understanding complexity theory and personality typology in relation to behavioral actions is paramount if change is to occur.
Correspondence: Mary Laurenson University of Hull, Faculty of Health and Social Care, Department of Health Professional Studies, Cottingham, Hull HU6 7RX, United Kingdom

Tel +44 I482 464603

Email m.c.laurenson@hull.ac.uk 
Complexity theory was originally a natural sciences concept; however, its application can be used to explain contextualized human behavior and actions. This is achievable by connecting Burton's description of complexity, that "interaction between components can produce unpredictable behavior," ${ }^{12}$ with Kernick's suggestion, that complexity:

Sees systems undergoing continual transformation in a network of non-linear interaction. The emphasis moves away from prediction and control to an appreciation of the configuration of relationships amongst a system's components and an understanding of what creates patterns of order and behaviour among them. ${ }^{13}$

Thus, Burton and Kernick underline the importance of interactive relationships in human systems and provide a rationale for exploration of collaborative processes. Wright ${ }^{14}$ suggests that care sector workers need to equip themselves with collaborative working skills and that a comprehensive IPE curriculum could achieve this. However, for IPE and IPW to become successful also requires H\&SC organizations recognizing divisions and barriers inhibiting practice.

\section{Aim}

The aim of this paper is to examine interprofessionalism through the lens of communication and relationships. The study draws upon personality typology, learning strategies, and interventions to promote change and analyzes factors encouraging or inhibiting collaboration across different professional and informal carer groups.

\section{Methods}

The research reported here is part of a larger mixed methods comparative study of five groups (nurses, social workers, care managers, police, and informal carers). ${ }^{1}$ This paper utilizes the qualitative data and provides a comparative analysis of respondents narratives examining the similarities and differences between organizations, professional groups and informal carers' approaches to care provision.

\section{Research sample}

Data were collected from the four service sectors of statutory, private, voluntary, and informal provision. Perspectives were obtained from four distinct groups of professionals, working within different organizations, with different theoretical and practical frameworks, and from a fifth group of the informal carers to gain the views of both carers and service users. The groups consisted of: nurses $(\mathrm{n}=17)$ working within the framework of either medical or nursing models; social workers $(\mathrm{n}=18)$ covering social models; care managers ( $\mathrm{n}=18$ ) covering business and management models; police $(\mathrm{n}=16)$ covering the legal model; and informal carers $(\mathrm{n}=12)$ covering the consumer model.

Participants were chosen using purposive nonprobability sampling ${ }^{15}$ to reflect particular qualities of the people, their relevance to the topic of investigation and those most likely to provide valuable data. ${ }^{16}$ The inclusion criteria were that all participants in the professional groups had undertaken training to achieve competence in their role. The informal carers required personal experience of caring on an ongoing basis for a minimum of 1 year, but had no formalized H\&SC professional qualification. All participants had collaborative working experience in education and practice.

\section{Ethical considerations}

Ethical approval was obtained from a higher education institute (HEI) with consent gained from cohort groups. A covering letter outlined their voluntary involvement and detailed informed consent, privacy, confidentiality, and anonymity. Respondents were referred to by occupational status to avoid individual identification and bias was avoided by delivering the same semi-structured schedule during interviewing.

\section{Data analysis}

In this qualitative study data analysis was carried out to organize and examine data collected through semi-structured interviews. Data were transcribed verbatim to obtain narratives and descriptions and to elicit face-value meanings through content and comparative analysis. This enabled the discovery of the underlying causes and motivations behind the similarities and differences in the respondents' experiences of working in health care teams. Morse ${ }^{17}$ described two parts to content analysis: latent and manifest analyses. Latent analysis reviews the transcript in relation to the whole interview to discern covert and overt meaning of the respondents' words. Manifest analysis searches the transcript for words and phrases congruent to the research questions. In this study both latent and manifest approaches were adopted to gain insight from the narratives of the respondents lived experiences. The comparative approach provided an understanding of the complexity of different organizations, professional groups, and informal carer approaches to care provision and delivery within H\&SC care sectors. The comparison sharpened the focus of the analysis and provided an opportunity for new perspectives to be considered.

A Heideggerian hermeneutic approach ${ }^{18}$ provided an interpretative perspective with which to understand the narratives. To do this, the researcher acquired a sense of the whole 
experience and extracted significant statements to formulate meanings and validated these through discussions with the respondents. The findings utilized a selection of the narratives from respondents to illustrate and illuminate the points being made. The overall process aided the production of data summaries, graphs, and tables and elicited emerging themes related to experiences of IPW and IPE.

\section{Findings of experiences of IPE and IPW}

This section provides an overview of similarities and differences provided through a sample of the narratives from each group. These included: teamwork development during IPE; skills and knowledge requirements; preferred IPE delivery methods for IPW; and personality types.

Firstly, the respondents' narratives outlined teamwork development during IPE. Nurse's responses highlighted limitations due to the lack of initiatives offered:

Team working was one of those sessions we considered to be time wasting. We were supposed to work together on assignments ... some wouldn't pull their weight [...]. It was difficult to complain because part of the marking criteria was based on effective team working. [N7]

We did some sessions on teamwork during our training $[\ldots]$ with other nurses. We did scenarios [...]. We had to imagine that we belonged to the other profession and we clearly didn't. [N12]

Social work responses described similar experiences:

Education providers have a lot of work to do here ... sent us off in groups to work through case studies or scenarios, but no other professionals were involved. [SW5]

Another social worker added that assessment methods simply served to provide incentives to pretend to collaborate rather than to genuinely engage:

In theory we should be trained alongside other professionals. In practice we have to have competency criteria of working with others evidence, you behave yourself because otherwise they won't sign you off [,] [SW9]

whilst another social worker outlined particular professional requirements to undertake their role:

I don't mind working as part of a team as long as they take my professional views into account. Social work training gives you a particular outlook, we deal a lot with antioppressive practice. [SW10]
Care manager responses outlined how the process had both positive and negative outcomes for developing their professional roles:

I wasn't really interested in the softer options such as team working and interpersonal interaction [...] I already had a natural ability for these areas and I needed to concentrate on the financial and legal aspects. [CM1]

We undertook interpersonal interaction which included team building with other H\&SC professionals. I enjoyed the sessions on team building and put the skills learnt into practice [...]. It's helped me be successful in my role. [CM15]

Police responses outlined the value of their initial police training and ongoing training with other professionals as a beneficial way to break down barriers:

Team working is important, communication is a key aspect of my job ... you learn to listen and record accurately [...]. Looking back, my initial police training was extremely valuable even though it was a long time ago. I've continued training throughout my career. [P5]

The initial training emphasized working as part of a team was essential to good police work ... with the general public it part of your people skills. [P12]

The advantage was to break down barriers between services, see how different agencies and professionals work. [P8]

Informal carer responses expressed feelings of exclusion:

It would be nice to feel part of the team, but usually the nurses or social workers take charge. [IC2]

Sometimes they [professionals] involve you but more often they don't. [IC6]

Part of the team of carers don't make me laugh, they [professionals] don't include, involve, or discuss much with me. It's pushing for information, resources and help all the time. Sometimes you get it, most times you don't - it's very frustrating. [IC11]

The narratives provided examples of positive and negative experiences of collaboration. However, perceptions of the insular nature of the experience are notable and it was generally considered that existing IPE was not working well. This indicates that interventions are needed to improve standards by enhancing communication and interaction. Previous research suggests IPE can increase professional competence to improve service delivery. ${ }^{19-22}$ Furthermore, 
Hammick $^{23}$ cites its ability to provide acknowledgment and respect of professional identities. An important point being made in the narratives was that, whilst overcoming barriers, it was important nevertheless to retain boundaries between professional areas. This enables each professional to remain clear about their role and what is expected of them and others in relation to service delivery.

This research demonstrates that all the groups had varying degrees of satisfactory experiences and concluded that interprofessional collaboration was necessary, but remained unsure of its achievability. Some felt their initial professional education, training, and continuing practical experience was sufficient for their career lifetime, and that they, in consultation with their own organizations and awarding bodies, should take responsibility for developments.

Respondents indicated that IPE was needed after qualification to increase IPW, but again related these to specific roles, responsibilities, and knowledge of their organizational aims and objectives. Some respondents' stated competency attained for qualification was sufficient for quality service provision, albeit specific reference was made to maintaining and improving professional knowledge as a criterion for professional accountability.

\section{Skills and knowledge requirements}

The respondents suggested that skills needed targeting to specialty requirements rather than to generic ones. Hence the respondents were asked to rank skills and knowledge requirements in order of their perception of their importance. Figure 1 demonstrates that the attribute they ranked as most important was interpersonal interaction, followed by team building and group work, management and leadership, decision making, and, finally, professional understanding of organizations and cultures.
Barr $^{24}$ cited shared learning as a way forward, but despite progress this initiative has not resolved the lack of understanding between professionals or organizational differences, or the fact that not all HEIs have utilized IPE/IPW frameworks. The majority of respondents' experiences testified to this explicitly as demonstrated in a sample of professional responses.

A nurse's response demonstrated challenges in collaboration:

I learnt a bit about Social Services, but I don't think the social workers learnt about the NHS [National Health Service]. The social workers I talked to seemed intent in turning everything to their viewpoint. [N14]

A care manager's response reinforced this perception:

We shared social policy sessions with social workers $[\ldots]$ they literally took over and our viewpoints were never addressed. We never shared any sessions with nurses, had we done so I think it might have been different. [CM10]

Social workers' responses highlighted professional differences and role requirements:

Counseling was shared with care managers ... they focused on financial aspects and we were left to deal with the social aspects, so there was nothing new really. They thought we didn't understand the financial aspects, it was surreal. [SW13]

Our educational training was very insular and ... I was intent in learning my roles and responsibilities not those of others. [SW17]

In an attempt to resolve these challenges whilst still retaining a professional identity the respondents were presented with a list of possible topic areas to rank in order of importance of a greater understanding of IPW. Figure 2 summarizes their responses.

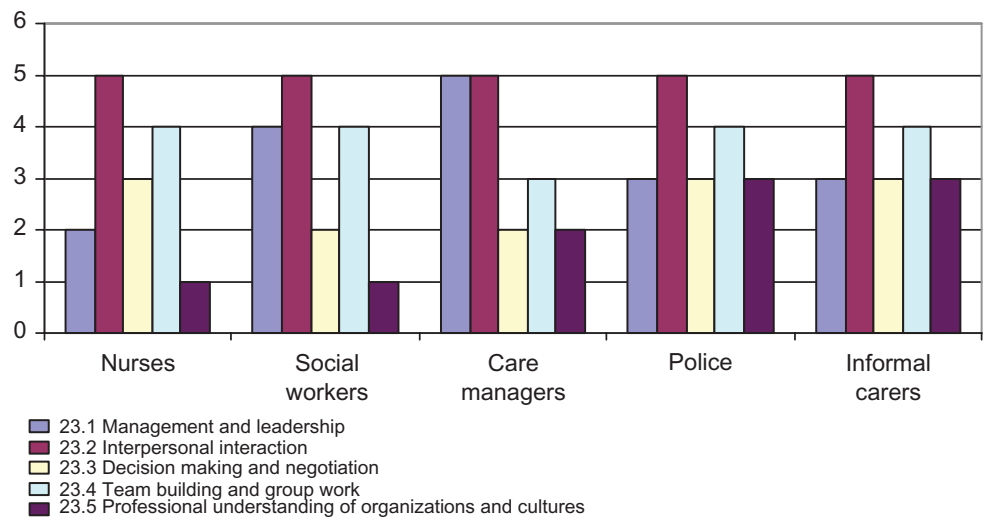

Figure I Graph showing how the groups ranked skills and knowledge requirements.

Note: 5 = highest rank, I = lowest rank. The numbers below the graph represent the question numbers. 


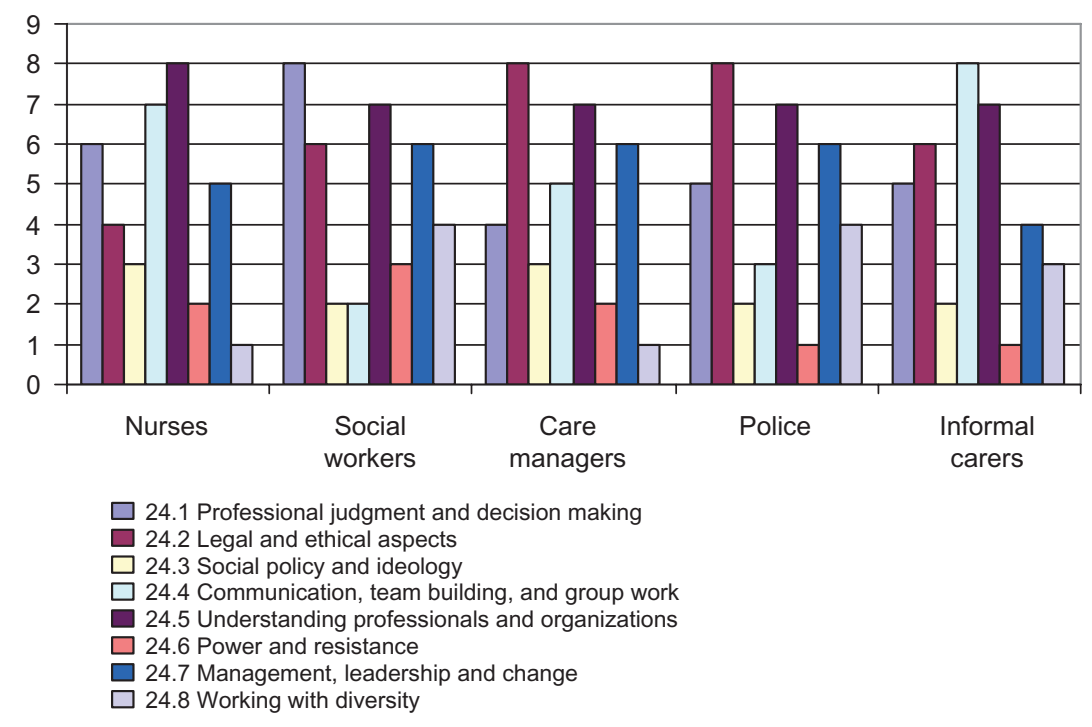

Figure 2 Graph showing how the groups ranked IPE topics.

Note: $8=$ highest rank, I = lowest rank. The numbers below the graph represent the question numbers. Abbreviation: IPE, interprofessional education.

The choices demonstrated that: nurses ranked understanding professionals and organizations as their first choice. Social workers ranked professional judgment and decision making as their first choice. Care managers and the police ranked ethical and legal aspects as their first choice, while informal carers chose communication, team building, and group work. Overall, the most important topic was considered to be understanding professionals and organizations; this is clearly a topic that would lend itself very effectively to IPE. The other topics in overall rank order were: legal and ethical aspects; team building and group work; professional judgment and decision making; management, leadership, and change; working with diversity; social policy and ideology; and, finally, power, resistance, and change. However, all have the potential to be used as effective IPW topics, assuming an appropriate delivery method is devised.

\section{Preferred IPE delivery methods for IPW}

Respondents were asked to consider three IPE delivery options to comment upon:

- Shared learning (different professional groups taught and assessed together on common content)

- Common learning (topics common to the different professional groups taught and assessed within professionspecific programs)

- Problem-based learning (PBL; participants work cooperatively in groups of different professionals to seek solutions to real life problems)
The outline in Table 1 demonstrates the preferences of each group with regards to learning delivery methods.

The distribution of the use of delivery methods across the total sample consisted of $28 \%$ favoring shared learning, $20 \%$ common learning, and $52 \%$ PBL. The majority of respondents $(52 \%$ overall; $47 \%$ of nurses, $61 \%$ of care managers, and $100 \%$ of police) favored PBL and this method is recognized as having wide applicability to vocational education programs. For example, Pincus ${ }^{25}$ states students undertaking PBL during their education have more favorable attitudes than students undertaking traditional instruction. Alternatively, social workers' (61\%) preferred common learning assessed within profession-specific programs, and this hints at their disinclination for interdisciplinary working. This was elaborated upon by a social worker's comment:

Common learning suits social work because we can be assessed in our own discipline by social work educators who know the score in our work. I don't think nurse educators would see our work in the same way[,] [SW13]

Table I Preferred delivery method for each occupational group

\begin{tabular}{llll}
\hline Occupational group & \multicolumn{2}{l}{ Delivery method } \\
\cline { 2 - 4 } & Shared & Common & PBL \\
\hline Nursing & $18 \%$ & $35 \%$ & $47 \%$ \\
Social work & $22 \%$ & $61 \%$ & $17 \%$ \\
Care manager & $39 \%$ & $0 \%$ & $61 \%$ \\
Police & $0 \%$ & $0 \%$ & $100 \%$ \\
Informal carer & $60 \%$ & $0 \%$ & $40 \%$ \\
Total & $28 \%$ & $20 \%$ & $52 \%$ \\
\hline
\end{tabular}

Abbreviation: PBL, problem-based learning. 
whilst the informal carers $(60 \%)$ preferred shared learning, as one cited:

If we shared the learning perhaps then they would understand what it's like for us. We get overlooked and I think we are undervalued and this way they just might listen. [IC12]

This is a common theme for informal carers, and it is increasingly apparent that informal carers are likely to be major beneficiaries of IPE. Just over half of the respondents (52\%) favored PBL as their preferred learning method. This fits very well with both IPE and IPW because it deals with complex problems from real life situations which enable students to discover concepts and interconnections by analyzing problems, sharing findings, and formulating and evaluating solutions. On the other hand, traditional teaching can be considered to provide abstract knowledge which is memorized and then may be applied to problems later in practice settings. However, PBL has the ability to help student professionals to develop higher-level critical thinking skills, rather than just allowing them to assimilate facts, terms, and definitions. Consequently, PBL is suitable for interprofessional approaches as it facilitates an integrated approach to the development of skills to cope with the changing nature of H\&SC provision. Respondents in this study stated that their experiences were limited by educators' tendencies to use case studies or scenarios for specific problems for discussion without actual input from each occupational group.

Additionally, if PBL is introduced by the various professional educators it could enable participants to view problems from a range of different professional perspectives. This is in accord with the concepts of IPE and IPW, resulting in a better understanding of different professional cultures, in order to find solutions to the H\&SC problems being faced by service users. However, whilst interaction between groups of professionals and team members is essential to IPW, it was apparent that this was not always present in educational interventions or successful in practice.

\section{Personality types}

All respondents commented on aspects of personality enhancing or hindering IPW and a narrative sample of these responses are provided covering different aspects. A care manager highlighted personality when discussing particular professions:

I think nurses by their very nature are more compliant, more conforming and social workers, from my experience are more controversial, more confrontational. [CM6]
A social worker expanded on this theme by discussing personality in relation to teamwork:

I don't mind working as part of a team as long as they take my professional views into account. Social work training gives you a particular outlook [...] you have to be a strong character. [SW10]

One police officer commented on personality and how their training helped them in understanding differences in people:

In our training we deal a lot with understanding others, we learn to observe and note how others are reacting. You get different types of people and it's important to understand them. [P3]

A second police officer related understanding personality more to working with other professionals as well as members of the general public:

There are sometimes difficulties in working alongside other professionals, especially social workers [...]. They don't always [...] understand where people are coming from. Nurses are [...] easier to deal with. I haven't had the opportunity of working with care managers yet. In our line of work we have to understand how people tick. We deal with so many different people. [P6]

Three informal carers highlighted differences between the professionals and highlight issues of power and personality:

Social workers $[\ldots]$ put their own point forward even when they say they are supporting the service user. I don't understand them [...]. It's a real struggle. [IC7]

The professionals I have come into contact with [...] come at things from different ways, I'm not sure if this is because of their job training or because of their own outlook. [IC11]

Some [professionals] are nice, others not so nice. I'm not talking about these differences depending on whether I get what I need. I guess we are all different and you just have to know where people are coming from. I'm not sure if it is their training or just them. [IC4]

This personality theme is important because understanding personality types influences understanding of individual thought processes leading to behavior actions. It was evident from responses that understanding other professionals was challenging. This was further demonstrated in a sample of the responses about the impact of professional dominance on professional relationships. 
Nurse response:

Social workers often ride rough shod over others opinions or suggestions. [N6]

Social worker response:

This can vary from meeting to meeting and may be influenced by several factors: personal style, confidence, knowledge of the case, area of knowledge. Social workers and the police always seem to outstrip other professionals. [SW4]

Care manager response:

If police are involved they tend to take the limelight as it involves aspects of law etc [...]. Professionals can't always fit the "role," they are people with personalities and some dominate conversations quite naturally. [CM18]

Police response:

Social workers $[\ldots]$ tend to have strong views and are vociferous in their arguments. [P2]

Informal carers' responses:

Social workers [...] are very verbal and domineering. [IC3]

Social workers always put their penny worth in and on most occasions pay lip service to informal carers. [IC6]

Personality type is widely recognized as influencing interpersonal processes, not only by impacting upon one's own preferred style of interaction, but our interpretation of the needs and preferences of others.

\section{Discussion}

Although teamwork can be developed to some degree through the standard approaches to IPE, this research serves to emphasize professional individuality and highlights how people involved in H\&SC function within interprofessional groups depending upon their personality type. Jung's philosophy of personality typology of extraversion and introversion outlines eight personality types (used by people in varying degrees and frequencies) to gain an understanding of people's behavior and actions (cited by Stevens). ${ }^{26}$ Understanding behavior and actions are key aspects of IPW. Further development was formulated through the MyersBriggs Personality Type Indicators ${ }^{27}$ and by a temperament theorist ${ }^{28}$ who indicate personality types as persistent characteristics throughout the life course. Their premise is that, whilst individuals display a range of behaviors, they have certain preferred ways of operating that are adopted more easily and readily.
When considering the groups most dominant in communications the respondents' overwhelmingly cited social workers. In terms of personality types, social workers were viewed as extraverts, whilst nurses and informal carers were viewed as introverts and the police and care managers cut across both. Arguably, social workers require an extraverted personality type to overcome disabling, oppressive practices, but other professionals expressed difficulty understanding their behavior. Hence, learning about personality types provides an opportunity for professionals to gain insight into each other's ways of thinking and behavior. ${ }^{27,28}$ However, traditional education overlooks personality typology, focusing instead on logic rather than subjective approaches. This imbalance could be rectified by educationalists implanting personality typology into educational strategies to demonstrate how people process and act on information differently. For this reason, a H\&SC curriculum review is needed by educationalists to include personality typology so it facilitates communication and improves mutual understanding to enhance collaboration.

Covey $^{29}$ states that understanding personality types enables individuals to value differences in mental, emotional, and psychological areas and to realize that others view the world differently. Understanding this allows individuals to stop projecting their own particular personality type over that of others so that it allows them to see the world from other perspectives and suggests it provides an opportunity to change perceptions by looking beyond their own interpretation of the world..$^{27,28}$ Additionally, Bennis and Nanus ${ }^{30}$ suggest that understanding personality types can help in leadership of the workforce as managers and leaders would be able to gain an understanding of their workforce. Profiling personality types does not mean that all individuals will fall into one category or another, or that an extraverted type cannot undertake introverted-type activities, but it provides an indicator of how an individual might act or react in a collaborative situation.

There are many advantages to be gained in working interprofessionally, as working "together" rather than "alongside" can energize people and result in new ways of tackling old problems. Such synergy can result in a synthesis of new ideas. ${ }^{1}$ Key aspects of enhancing collaboration are understanding complexity and personality when considering the interrelatedness of systems and processes that could be utilized in care provision. Teamwork skills development during IPE through the use of PBL, complexity theory, and personality typology will facilitate knowledge and understanding around how different organizational, professional, and personal outlooks impact on working relationships. For any team to form and perform effectively there are certain stages 
the group goes through as outlined by Tuckman's “storming, forming, norming, and performing" typology. ${ }^{31}$

Tuckman stresses that a group of people coming together does not necessarily mean they become an effective team. The effectiveness of the team depends on various factors including its function, cohesiveness, structure, ability and how it is led and managed. Cross-functional or interprofessional teams face additional challenges that also have to be acknowledged and addressed. McKenna ${ }^{32}$ recognizes that cross-functional teams are usually drawn from people with broadly similar levels of professional hierarchy and status, but whose professional background is diverse.

The process of becoming a team takes time and trust develops slowly. The very nature of these groups can mean that team members can frequently change or drop in and out depending on the nature of the situation being addressed, or at different stages of the group's life cycle. ${ }^{33}$ Personality factors and team roles can be impacted on by changes in team members. Time pressures and the passage of time can often lead to discussion of individual cases or situations being severely limited; hence the need for the team to operate effectively and with a high degree of professional trust and respect is important.

One of the purposes of IPW is to ensure effective knowledge transfer and good decision making between the various represented parties. Oborn and Dawson examined the working of a multidisciplinary team in a health setting and concluded:

$[\ldots]$ healthcare delivery $[\ldots]$ means that $[\ldots]$ team design and work based relationships, dimensions of authority and accountability need explicit consideration [...]. This point, however, is rarely [...] embedded in policy guidelines as it is assumed that personal interaction somehow comes naturally if formal arrangements are made. ${ }^{34}$

This emphasis on the importance of leadership and management of the team is crucial to developing a shared language and promoting understanding amongst the various individuals and professional interests represented in the team. A facilitator must have professional respect along with skills in moderation, negotiation, and communication to bring out similarities and differences so solutions can be sought. However, acknowledging that personal interactions, respect, and trust do not occur naturally is important and needs to be embedded into policy development and professional training. Initial professional training and continuing professional development (CPD) provides the opportunity to integrate theory with practice in the areas of team working and personality traits.
For interprofessionalism to succeed, changes are required in professional relationships, so that professionals can act as agents of change and accept different perceptions when delivering care services to meet the best interests of those being cared for. If this does not occur then it is unlikely that interprofessionalism will benefit those it is intended to help. IPE requires knowledge about the experiences of individual and organizational processes to be placed at the center of a core curriculum of education. Previous conventional education and training does not address the needs of a diverse changing care environment, and initiatives to instill IPE need to include different professional groups, rather than subsections of those working in the same care area, to meet the needs of a changing society.

Leadership theories and management styles impact upon collaborative practice and managers and leaders need to develop collaborative relationships through teamwork practices. Their understanding of different personality types could help in conflict management and resolution with individuals, groups, and organizations. Chen et al highlighted the importance of recognizing personality and teamwork, stating that "personality and team context should be considered together so as to improve team knowledge integration and team performance." 35

Student professionals need to gain an understanding of other professionals and understand different personalities to be effective practitioners, as successful relationships are based on trust and mutual respect of others' viewpoints. Respondents mentioned courses in psychology where they discussed transactional analysis, Erikson, Freud, Gestalt, Maslow, Pavlov, and Skinner, but felt these did not help in understanding how other professionals thought processes worked. Understanding different personality types could aid in collaborative practice and teamwork competencies by providing an understanding of the diverse thought processes of professionals and service users, rather than insular roleplaying scenarios being carried out within separate disciplines.

The IPE curriculum needs to take all these aspects into account and deliver a curriculum from the starting point of academic and professional life. It can also be incorporated into other H\&SC in-house training, such as that undertaken by police or voluntary organizations. This could be continued for all professionals by CPD through the life-long learning agenda. The way forward in the professional education curriculum is to implant interprofessionalism as a core requirement with students having the opportunity to mix with a range of other students working towards professionalization. 
In year 1 (of prequalifying courses), the curriculum needs to provide students with the opportunity to understand governmental initiatives and to gain an awareness of health and social policies to understand the modernization agenda and organizational and professional change. In year 2, students need an understanding of the different management and leadership styles, as well as interpersonal relationships to develop positive approaches to team and group work participation and cooperation. In year 3 , critical thinking and analytical development has to be undertaken and the recommendation is that this can be done through a PBL using a real world approach to develop student problem solving skills.

In terms of interventions, a thematic PBL is suggested to cater for professionals specializing in a particular field (such as child care, youth work, adult care, care of the older person, etc) so concepts can collectively be considered from their professional stances so solutions can be transferred to specific contexts. A major advantage of PBL is the integrated interaction over and above traditional learning strategies to enable an understanding of each other's perceptions. In this research, the choice of preference outlined by the respondents from the knowledge and skills list was interpersonal and communication skills and this fits in well with the PBL initiatives. The respondents' first choice of learning delivery methods for IPE was PBL, as they asserted that, if undertaken correctly, it would allow them to work with and understand other professional approaches and so fits in well with understanding personality types. The respondents' first choice of modules was understanding professionals and organizations and this also fits in well with the concept of understanding personality types.

In a complex $\mathrm{H} \& \mathrm{SC}$ system it is necessary for educators, organizations, professionals, informal carers, and service users to work together to find solutions to current and future H\&SC problems. PBL lends itself to dealing with all of the issues related to interprofessional collaboration as it has the ability to better equip workers with problem-solving skills for practical application than traditional linear programs have done. ${ }^{36,37}$ However, what is also evident is that structural change in H\&SC institutions is needed and that HEIs have a part to play in this process by freeing themselves from traditional linear frameworks and embracing the diversity of teaching strategies and human psychology into curriculum development. ${ }^{36-38}$

\section{Conclusion}

Knowledge and understanding of complexity theory, personality types, and PBL initiatives provided through curriculum intervention could elicit understanding of others actions and reactions and ultimately benefit service users. For this to be instilled into practice requires leadership and management in education and practice settings. Interprofessional working is regarded as imperative and its failure is a contributory factor to shortfalls in service provision. The complexity of interprofessionalism is not merely attributable to different professional ideologies, but differences in people. Educational intervention needs to extend beyond "know that" to "know how," with "know how" based upon experience through experiential learning/PBL. However, recommendations for IPE need to move beyond bland statements about its virtue to specific recommendations for its practice.

This paper advocates interventions focusing upon the nature of relationships and recognizing communication as a large part of this. The implications of change in H\&SC roles and the ability of professionals to work interprofessionally to meet future needs will require changes in $\mathrm{H} \& \mathrm{SC}$ education and training. New developments in complexity theory and IPE also raise concern about HEIs continuing with a traditional linear framework when H\&SC organizations are becoming more complex and diverse. The findings of this paper reaffirm the importance of understanding personality in teamwork and recommend a greater use of PBL strategies to promote effective collaboration and negate differences that inhibit the delivery of quality care provision.

\section{Disclosure}

The authors report no conflicts of interest in this work.

\section{References}

1. Laurenson M. Interprofessionalism in Health and Social Care-working towards an inclusive framework [EdD thesis]. Huddersfield, UK: University of Huddersfield; 2007.

2. Laurenson M, Brocklehurst H. Interprofessionalism, personalization and care provision. Br J Community Nur. 2011;16(4):184-190.

3. NHS is failing to meet even the most basic standards of care for older people [webpage on the Internet]. London: Parliamentary and Health Service Ombudsman; 2011. Available from: http://www.ombudsman. org.uk/about-us/media-centre/press-releases/2011/nhs-is-failing-tomeet-even-the-most-basic-standards-of-care-for-older-people,-warns. Accessed November 34, 2011.

4. Care Quality Commission. The State of Health Care and Adult Social Care in England. London: Care Quality Commission; 2011:1-66. Available from: http://www.cqc.org.uk/sites/default/files/media/ documents/state_of_care_2010_11.pdf. Accessed November 28, 2011.

5. Humphris D, Masterson A. New Clinical Roles: A Guide for Healthcare Professions. London: Harcourt Brace; 2000.

6. Humphris D, Hean S. Educating the future workforce: building the evidence about interprofessional learning. J Health Serv Res Policy. 2004;9 Suppl 1:24-27.

7. Kendall L, Lissaur R. The Future Health Worker. London: Institute for Public Policy Research; 2003.

8. Trevillion S, Bedford L. Utopianism and pragmatism in interprofessional education. Social Work Education: The International Journal. 2003; 22(2):215-227. 
9. Davies C. Getting health professionals to work together. $B M J$. 2000;320:(7241):1021-1022.

10. Finch J. Interprofessional education and teamworking: a view from the education providers. BMJ. 2000;321(7269):1138-1140.

11. Barr H. Interprofessional Education: Today, Yesterday and Tomorrow. London: Learning and Teaching Support Network; 2002.

12. Burton C. Introduction to complexity. In: Sweeney K, Griffiths F, editors. Complexity and Healthcare: An Introduction. Oxon: Radcliffe Medical Press Ltd; 2002.

13. Kernick D, editor. Complexity and Healthcare Organization: A View From the Street. Oxon: Radcliffe Medical Press Ltd; 2004.

14. Wright S, editor. Changing Nursing Practice. 2nd ed. London: Arnold; 1998.

15. Denscombe M. The Good Research Guide: For Small Scale Social Research Projects. Buckinghamshire: Open University Press; 1998.

16. Polit D, Hungler B. Nursing Research: Methods, Appraisal and Utilization. 4th ed. Philadelphia: Lippincott; 1997.

17. Morse J. Qualitative Nursing Research. California: Sage; 1991.

18. Heidegger M. Being and Time. New York: Harper and Row; 1962.

19. Barr H. Competent to collaborate: towards a competency-based model for interprofessional education. J Interprof Care. 1998;12(2):181-187.

20. Wilcock PM, Headrick LA. Continuous quality improvement in health professions education. J Interprof Care. 2000;14(2):Special issue.

21. Wilcock PM, Headrick LA. Interprofessional learning for the improvement of health care: why bother? J Interprof Care. 2000;14(2): 111-117.

22. Wilson P, Pirrie A. Multidisciplinary Team-working Beyond the Barriers? A Review of the Issues. The Scottish Centre for Research in Education: Glasgow; 2000.

23. Hammick M. Interprofessional education: evidence from the past to guide the future. Med Teach. 2000;22(5):461-467.

24. Barr H. Lifelong learning unlimited: new horizons, and new hazards for the professions [professorial lecture, October 20, 1999]. London: University of Westminster; 1999.
25. Pincus KV. Introductory accounting: changing the first course. In: New Directions for Teaching and Learning. 1995;61:89-98.

26. Stevens A. Jung: A Very Short Introduction. Oxford: Oxford University Press; 2001.

27. Briggs Myers I, Myers B. Gifts Differing: Understanding Personality Type. Oxford: Oxford Psychologists Press; 1993.

28. Keirsey D. Please Understand Me II Temperament, Character, Intelligence. New York: Prometheus Nemesis Book Company; 1998.

29. Covey S. The Seven Habits of Highly Effective People. New York: Simon and Schuster; 2004.

30. Bennis W, Nanus B. Leaders: The Strategies for Taking Charge. New York: Harper Business; 1997.

31. Tuckman BW. Developmental sequence in small groups. Psychol Bull. 1965;63:384-399.

32. McKenna E. Business Psychology and Organizational Behaviour. Hove: Taylor and Francis; 2012.

33. Belbin RM. Team Roles at Work. Oxford: Butterworth Heinemann; 1993.

34. Oborn E, Dawson S. Knowledge and practice in multidisciplinary teams: Struggle, accommodation and privilege. Human Relations. 2010;63(12): $1835-1857$.

35. Chen ZJ, Xin Qin X, Vogel D. Is cooperation a panacea? The effect of cooperative response to task conflict on team performance. Systems Research and Behavioral Science. 2012;29:163-178.

36. Albanese MA, Mitchell S. Problem-based learning: a review of the literature, its outcomes and implementation issues. Acad Med. 1993; 68(1):52-81.

37. Cooper H, Braye S, Geyer R. Complexity and interprofessional education. In: Learning in Health and Social Care. 2004;3(4):179-189.

38. Fraser SW, Greenhalgh T. Coping with complexity: educating for capability. BMJ. 2001;323(7316):799-803.
Journal of Healthcare Leadership

\section{Publish your work in this journal}

The Journal of Healthcare Leadership is an international, peer-reviewed, open access journal focusing on leadership for the health profession. The journal is committed to the rapid publication of research focusing on but not limited to: Healthcare policy and law; Theoretical and practical aspects healthcare delivery; Interactions between healthcare and society and evidence-based practices;

\section{Dovepress}

Interdisciplinary decision-making; Philosophical and ethical issues; Hazard management; Research and opinion for health leadership; Leadership assessment. The manuscript management system is completely online and includes a very quick and fair peer-review system. Visit http://www.dovepress.com/ testimonials.php to read real quotes from published authors. 